\title{
Doctors don't own medical knowledge
}

A $s$ the debate continues over whether a private-sector health care system should be implemented in Canada, I am left pondering a fundamental question: Who are the rightful owners of the vast compendium of medical knowledge: doctors or the public?

The most obvious answer points to physicians. As students, they endured many years in premedical studies, medical school and residency training. What is more, many accrued more than $\$ 100000$ in debt before graduating. ${ }^{1}$ One could argue that physicians have earned the responsibility of gatekeeper in respect to medical information. And in this role, they have also earned the right to information ownership.

While training at a hospital in Alexandria, Egypt, I was confronted by this fundamental question. Egypt has a multiple-tier health care system consisting of an impoverished public sector at one end and a technologically superior private sector at the other. Experienced physicians in the private sector are able to determine their patients' access fees, thus creating restricted access to their cache of medical knowledge. Patients in pursuit of the best possible care must thus pay for admittance. In this example the physician acts as the sole proprietor of his medical knowledge.

While studying at the University of Toronto last year, the issue of ownership over medical knowledge was casually discussed among my classmates with an experienced physician. In his view, the knowledge a physician gains in medical school is the property of Canadian taxpayers. For him, this knowledge is held as a "sacred covenant" - an innate trust - between physicians and patients with the promise that such knowledge will be administered justly and fairly throughout the community. According to this understanding, a more balanced relationship is instilled, whereby the physician acts as the custodian of knowledge, as opposed to its exclusive owner.

It is important to recognize where medical knowledge in Canada is generated. Most cutting-edge medical discoveries come from research institutes and hospitals, the majority of which are funded through federal and provincial government grant agencies, such as the Canadian Institutes of Health Research. ${ }^{2}$

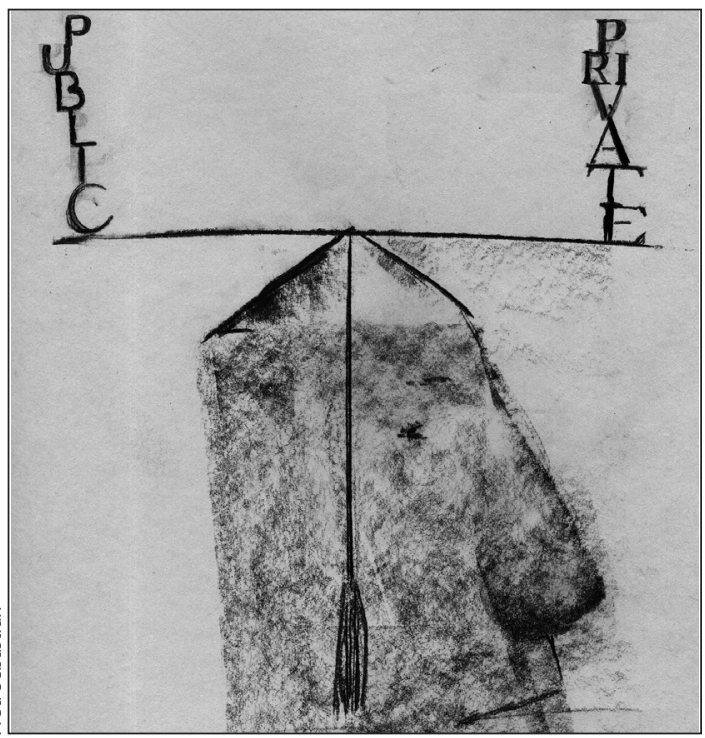

Estimates from 2004 and 2005 show that Canada's medical schools received a combined $\$ 2.37$ billion in annual funding toward health research. ${ }^{2}$ Should taxpayers, who both funded and actively participated in this research, not receive equal and fair access to this information?

The physician's education provides additional examples of this sharing. Medical students struggle to pay tuition, but the taxpayers of Canada bear a substantial part of the actual burden through their tax dollars. ${ }^{3}$ Furthermore, the monetary value ascribed to the dissemination of medical knowledge does not account for the many sacrifices patients make to enhance the education of physicians. What price can be placed on the generosity of a person who donates his or her body to science to assist future physicians in their understanding of anatomy? Similarly, can a price be placed on the thousands of patients who allow medical students to practise procedures on them in order to glean practical experience?

I was fortunate enough to witness the concept of medical knowledge being held as a "sacred covenant" through the professional values of an Egyptian surgical resident I met at the University of Alexandria. I was deeply inspired when he told me that even though it might be tempting to practise medicine in the United Kingdom, where he would earn a much higher salary and have access to superior resources, he ultimately chose to remain in Alexandria's public hospitals.

His reason was clear: the patients he met during his medical career have been his "greatest teachers." Consequently, he feels obliged to repay their kindness by allowing public access to his expertise. For this reason, he has no desire to leave the people who helped him refine his knowledge. They are, after all, the reason he has come to understand the ever-challenging and dynamic field of medicine. Without the people of Alexandria, he would not be the doctor that he is today.

\section{Tarek Abd EI Halim BSc}

Class of 2011

Faculty of Medicine

University of Toronto

Toronto, Ont.

\section{REFERENCES}

1. Sullivan P. Mortgage-sized debt the new norma for medical students. CMAJ 2003;169:457-8.

2. Kondro W. Thinking of med school? Where do you live? CMAJ 2007; 176:157-8

3. Snowdon \& Associates. Access to medical education in Canada: Do differing tuition regimes affect access and career choice? Number 35. Montréal (QC): The Canada Millennium Scholarship Foundation; 2008. p. 24

Have you got an opinion about this article? Post your views at www.cmaj.ca. Potential Salon contributors are welcome to send a query to salon@cma.ca. 